\title{
WHAT IS AN ICT PROFESSIONAL ANYWAY?
}

\author{
Clive Boughton \\ College of Engineering and Computer Science, Australian National University \\ Email: Clive.Boughton@anu.edu.au
}

\begin{abstract}
The intention of this paper is to instigate ongoing discussion surrounding the connected topics of ICT professionalism and the ICT profession. Part of that discussion needs to include suggestions of 'the way forward' for the development and recognition of an ICT professional body and the way it should govern/support/protect the professionals within.
\end{abstract}

\section{INTRODUCTION}

The intention of this paper is to instigate ongoing discussion surrounding the connected topics of ICT professionalism and the ICT profession. Part of that discussion needs to include suggestions of 'the way forward' for the development and recognition of an ICT professional body and the way it should govern/support/protect the professionals within. I want to start off by describing some of the types of people that I have personally met/observed during my time in the systems/software industry and also within academia. The type classifications are mine, are not formal, and carry no essential meaning other than what I have deigned to give them. They are like a loosely typed language: they only possess meaning in a chosen context, and I can change the meaning and context whenever I like. Hence the classifications to be presented are not to be interpreted as authoritative. The point in presenting these ICT types is to help to identify different angles to the accepted norms on the subject of professionalism, and to use them in a discussion on the state of professionalism and indeed the current state of the ICT profession.

To me individual professionalism (as a norm) requires a combination of several necessary characteristics, they being:

- competency,

- ethicity,

- knowledgeability,

- learning ability,

- care,

- $\quad$ and pride.

I believe that none of these characteristics alone, or as a subset, fully describes a professional. However, it is common for ICT people to attach to themselves the label of 'professional' whilst lacking one or more of the characteristics listed above. A more formal definition of professionalism 
will be provided later in the paper, and it will be used to help explore the subject of ICT professionalism. Aside from professionalism in ICT, it is not clear what the ICT profession is. Is it a combination of two (or more) different professions? Is it merely a label given to a broad range of computer, software, communication networks, electronics, and other practices and sciences? Again I will draw on more formal definitions to discuss the state of play of the ICT profession later in the paper.

\section{THE ICT (INFORMATION AND COMMUNICATIONS TECHNOLOGIES) TYPES}

The following descriptions are provided in the hope that readers have perhaps met people with many of the same traits and that they ponder the connection between the traits and "professionalism". The labels given to the "types" are intended to summarise overall capability and social interaction.

\section{The highly broadly technical and you know it}

They know their stuff and make sure everyone else knows they know their stuff. They have an excellent grasp of what they know, but it's usually the highly technical/detailed information with which they interest themselves. Presumably it provides a degree of comfort/control to know a whole heap of stuff with which few others have interest. They always have something to say when discussions move to their area of expertise and they nearly always make everyone feel inadequate or irritated on such occasions. Such discussions don't last long unless there's another "highly technical and you know it" sort of person participating - but then they tend to be the last people standing, when everyone else has gone. These people are usually competent and ethical, and often perform best under pressure - they love the challenges. They typically don't make great team players/managers because their organisational abilities only apply to themselves. When praised for their performance their attitude is typically one of: "What did you expect?" Diplomacy is not one of their strong traits.

\section{The highly broadly technical and you don't know it}

They are quiet/unassuming and know their stuff but generally others don't know that they know their stuff. They have an excellent grasp of lots of things, not just their ICT knowledge - but few ever know. They perform their work with a very high level of competence and due diligence, and are usually very ethical - they hate pressure though. They are typically very self-critical even when they are told that they have performed excellently. These people often squirm when praised - but in the end they do appreciate being wanted. Typically they will not volunteer their expertise and they're just as happy to occupy themselves learning new stuff if no-one bothers to include them in a team/task. These people definitely cannot manage anyone other than themselves, but at least they know it. They also know that there's a lot that they don't know and they often worry about this.

\section{The highly narrowly technical and you know it}

A little like the "highly technical and you know it" types, but they are usually newbies to the game and/or more immature. Every new problem put to them is solved using the 'one' technique they know really, really well. These people are often seen as a pain. They usually don't perform well even when they are given the opportunity to use their best knowledge assets - probably because 
they are not particularly good at solving complex problems. If these people resist learning new ideas, they become increasingly incompetent.

\section{The highly narrowly technical and you don't know it}

As with the "highly narrowly technical and you know it" types, every new problem put to them is solved using the 'one' technique they know really, really well. The trouble is others don't necessarily know that that is what is happening during a project and if not discovered early can be disastrous. These people are a pain because they stubbornly insist that they are right and that everyone else is wrong. Again, just like the "highly narrowly technical and you know it" types, they usually don't perform well even when they are given the opportunity to use their best knowledge assets simply because they are not particularly good at solving complex problems. These people typically resist learning new ideas and so remain incompetent.

\section{The big-picture broadly technical}

Tend to be the visionaries. They possess/understand enough/plentiful technical concepts/information to be able to provide effective plans of attack to solving large problems without being swamped with detail. These people are typically the engineers of the ICT industry and they usually possess a wealth of experience. They are competent and always prepared to learn more, but not usually detailed knowledge. They can be good leaders and managers, but they are best at analysis, architecture and design. Verification and validation of ideas are not their strong point, but they are very happy for others to provide that detail. These people know what they know and don't know, and are typically prepared to inform others of the same. Sometimes their ethics are questionable, especially when they produce solutions to large problems where the broader stakeholder community is not recognised, or simply ignored.

\section{The big-picture narrowly technical}

Unfortunately the industry is riddled with these people. They try hard to emulate the "big-picture broadly technical" but usually fail because they lack the experience or they have only ever worked within a narrow field of ICT, or within a single organization. These people typically only provide the same conceptually limiting solutions to all large problems to which they are presented. Put them outside their safety net and they flummox. They can behave unethically when under pressure or when others have great expectations of them - but this is often caused because they don't communicate what they don't know.

\section{The concepts only}

There doesn't seem to be too many of these people about these days. However, they typically possess very limited knowledge and understanding of the technical, process, quality, and people elements of the ICT industry. The try and make themselves seem important by producing a million (mostly crazy) ideas a minute. They do try and concentrate on human usage and efficacy aspects of ICT. That is not to suggest that good concepts should not be produced by people who've never been trained in ICT, but they are usually experts within other domains.

\section{The I can do}

Usually new graduates, very enthusiastic and keen to make their mark. Often quite smart but tend to be over-confident. These are good qualities for new professionals to possess, but they do have to 
be controlled/directed so that the individual builds on good professional behaviour. If uncontrolled all sorts of disasters can occur not only for the individual but for teams and organizations. If newbies, then expectations are typically not well-aligned with reality - this is not limited to ICT. However, there is a potential to assume that 'I can do' ICT graduates are somehow smarter and 'righter' than engineers, scientists, lawyers, artists, etc., and their bosses. These people can possess new ideas and new technology, but this does not mean that they should be in control.

\section{The I can't do.}

Perhaps these people have chosen the wrong vocation. They lack confidence. They struggle to remember/understand almost anything, and they always need training. These people are not selfmotivated and show low initiative. They don't want to be responsible for anything or anyone. Under pressure they usually fail to perform. These people probably have all sorts of other problems that override their professional responsibilities. However, given the right opportunity and environment they can change.

\section{The other professional}

There is a broad set of this type of people. However, from a professional viewpoint these are often the people who both criticise the ICT profession and contribute to the apparent parlous state of the profession typically by undertaking ICT-related work themselves (when they are not competent to do so) or making serious decisions on behalf of ICT professionals without seeking any advice/input from those professionals.

What have these different observed types to do with professionalism and professions? Well, for a start it seems apparent that there is a diverse range of people in the ICT industry, possessing a diverse (not necessarily adequate) range of knowledge, abilities and personalities. On the one hand, many of the people working in the ICT industry and academia belong to no professional body, such as the ACS, ACM or IEEE. However, many seem to work professionally and demonstrate very high ethical behaviour - often higher than any of the professional bodies might promote/expect. On the other hand, quite a number of people in the ICT industry do belong to a professional society [6], and possess minimal knowledge of any part of the ICT domain, display little competence, and some even occupy positions of importance/influence over others who are far more knowledgeable and competent. Often, for the latter 'professionals' it seems that personality is the most highly valued characteristic. Interestingly, whilst working as a scientific professional within the more traditional engineering and scientific domains I observed that positions of importance/influence belonged to those with appropriate knowledge and competence - their personality traits were a lesser factor in gaining such positions. Of course, this situation has another set of problems. I have had about 25 years experience as a software engineer at various levels. In all that time, although I have identified many different work practices, ethical attitudes and personalities, I have not been able to establish precisely what comprises an IT or ICT professional. Hence the question associated with this paper: "What is an ICT professional anyway?"

Since I am not sure of the answer to this question, it seems appropriate to start with one or more definitions of a professional. 


\section{THE PROFESSIONAL}

There are numerous definitions of "professional". To begin with, the typical dictionary (in this instance The Collins English Dictionary) contains definitions for the word professional such as:

1. of, or relating to, suitable for, or engaged in as a profession,

2. engaging in an activity for gain or as means of livelihood,

3. extremely competent in a job, a person who engages in an activity with great competence,

4. undertaken or performed for gain or by people who are paid,

5. a person who belongs to, or engages in one of the professions,

On interpreting such definitions I can understand why prostitutes, are sometimes deemed professionals. More definitive views of professionalism include strong reference to profession, professional development and professional bodies. Such a view might include the following [1]:

- $\quad$ Professionals are considered experts in their chosen vocation/field.

- Professionals possess a broad range of (systematic) knowledge with a theoretical base.

- Professionals are responsible to the public and/or community.

- Professionals possess a high degree of autonomy regarding their decision-making and behavior.

- $\quad$ Professionals are governed by a code of ethics, which:

$0 \quad$ is a statement of rules and values.

o intends to ensure a high quality of service.

o intends to guarantee competency of membership, honor and integrity.

0 is an expression of a professions' principles and what it expects of its members.

o emphasizes no personal gain at cost to others (co-professionals, clients, community etc.).

- The professional's system of rewards is primarily recognition for building up appropriate knowledge and experience, and furthering the respect of the profession.

- $\quad$ There is a system for testing the competence of members.

Maister [8] provides a more humanist-oriented view of professionalism, by de-emphasising the knowledge/skill aspects. To paraphrase Maister slightly, he believes that “... real professionalism has little to do with which business you are in, what role in that business you perform, or how many degrees you have. Rather it implies a pride in work, a commitment to quality, a dedication to the interests of clients, and a sincere desire to help." An important indication of the nature of professionalism made by Maister is that it is "... predominantly an attitude, not a set of competencies. ... skills you can teach, attitudes and character are inherent.”

The key traits of a professional are shown in Table 1, where they are presented as a set of criteria for professionalism. All but the last of these have been taken from the Texas Library Service [1]. The ultimate trait has been added by myself after having read Maister's views on professionalism [8].

It is interesting to apply the criteria in Table 1 to some of the ICT types described earlier. These are shown in Tables 2 and 3, where again the resulting summaries are drawn from my own experience and observations. 


\begin{tabular}{|l|l|}
\hline Training & $\begin{array}{l}\text { There is an extensive period of training, often after a combination of formal } \\
\text { education, training and apprenticeship; usually in a higher education } \\
\text { environment. }\end{array}$ \\
\hline Intellectualism & The intellectual component is dominant. \\
\hline Autonomy & Professionals usually have autonomy in their work. \\
\hline Judgment & $\begin{array}{l}\text { Professionals, because of their training, education, knowledge and } \\
\text { experience, may use their own judgment in determining the appropriate } \\
\text { approach to their clients or customers. }\end{array}$ \\
\hline Independence & $\begin{array}{l}\text { Professionals can work independently and charge fees or they can be part of } \\
\text { an organization. }\end{array}$ \\
\hline Service & $\begin{array}{l}\text { Professionals possess abilities to provide a valuable service to society and } \\
\text { operate with little or no self-interest. }\end{array}$ \\
\hline Dedication & Professionals are dedicated to services and institutions. \\
\hline Pride & Professionals take pride in the quality of their work. \\
\hline $\begin{array}{l}\text { Honest \& } \\
\text { Trustworthy }\end{array}$ & Professionals can be trusted to behave honestly in all matters. \\
\hline
\end{tabular}

Table 1: Criteria for Professionalism - From Texas Library Service [1] with the last criterion added by the author of this paper.

\begin{tabular}{|l|l|}
\hline Training & Usually possess a technical based degree. Also do much self-education. \\
\hline Intellectualism & Not usually dominant. \\
\hline Autonomy & Usually. \\
\hline Judgment & $\begin{array}{l}\text { Whenever allowed or are asked to advise, but more likely to criticize other } \\
\text { peoples' judgments. }\end{array}$ \\
\hline Independence & $\begin{array}{l}\text { Not usually. Confidence in own abilities does not usually extend to taking } \\
\text { on the responsibilities of being independent. }\end{array}$ \\
\hline Service & Usually. \\
\hline Dedication & Not usually. \\
\hline Pride & Usually. \\
\hline $\begin{array}{l}\text { Honest \& } \\
\text { Trustworthy }\end{array}$ & Usually. \\
\hline
\end{tabular}

Table 2: Highly broadly technical and you know it professionalism 


\begin{tabular}{|l|l|}
\hline Training & Usually possess a non-technical degree. Don't do much self-education. \\
\hline Intellectualism & Very little. \\
\hline Autonomy & Not usually but do try. \\
\hline Judgment & $\begin{array}{l}\text { Whenever the opportunity arises. These people make the judgments that the } \\
\text { ICT types in Table 2 criticise. }\end{array}$ \\
\hline Independence & Not usually. \\
\hline Service & Inconclusive observation. \\
\hline Dedication & Inconclusive observation. \\
\hline Pride & Sometimes. \\
\hline $\begin{array}{l}\text { Honest \& } \\
\text { Trustworthy }\end{array}$ & Often not honest about their knowledge/capability. \\
\hline
\end{tabular}

Table 3: Big picture narrowly technical professionalism

The reason for choosing the two particular ICT types in Tables 2 and 3 is simply that they are contrasting but nonetheless represent a significant percentage of the ICT industry membership. Slight variations within Table 2 would result when applying the criteria to the other "broadly technical" types described earlier. Similarly variations within Table 3 would result when applying the criteria to the other "narrowly technical" types. The "concepts only", "I can't do", and "other professional" types should probably be disqualified as professionals, let alone ICT professionals. One might conclude that there are no real ICT professionals. I doubt that's true. However, because there is a confusion of diverse backgrounds and training of people working in the ICT industry, it seems appropriate to create an effective way to identify the various professionals - the ICT professionals specifically.

How do we distinguish an ICT professional from other professionals working within the ICT industry? Perhaps the answer can be found by examining the profession that supports the ICT professional.

\section{THE PROFESSION}

Professions, usually exemplified in the form of an association/society/body of like-minded colleagues, are typically created to represent and support those who are accepted as accredited members ('qualified' professionals), and to maintain professional integrity, values and recognition. Hence, real professions have responsibilities to the professionals they purport to support. For example they: 
- create structures of subcultures for professionals.

- $\quad$ provide legal reinforcement for the activities of professionals.

- $\quad$ strive to provide environments of public acceptance.

- $\quad$ promote ethical practices.

- $\quad$ define penalties for professionals who work against the tenets \& practices of the profession.

The traits of a profession are summarized in Table 4, which has been taken from the American Management Association's Handbook of Project Management.

\begin{tabular}{|l|l|}
\hline $\begin{array}{l}\text { Exclusive control - esoteric and systematic } \\
\text { BOK (body of knowledge) }\end{array}$ & $\begin{array}{l}\text { Members have a monopoly on understanding and } \\
\text { applying the BOK. }\end{array}$ \\
\hline Autonomy of practice & Members control the standards of the society. \\
\hline Norm of altruism & Members act in the best interest of client. \\
\hline Authority over clients & $\begin{array}{l}\text { Professionals control the client/practitioner } \\
\text { relationship. }\end{array}$ \\
\hline Distinctive occupational culture & $\begin{array}{l}\text { Occupation is set apart by a distinctive set of } \\
\text { norms, values, and symbols. }\end{array}$ \\
\hline Recognition & $\begin{array}{l}\text { Usually legal requirement for specific training } \\
\text { and preparation prior to practice. }\end{array}$ \\
\hline
\end{tabular}

Table 4: Traits of a Profession - From the American Management Association's Handbook of Project Management [2].

The Software Engineering Body of Knowledge [4] provides a characterisation of an engineering profession as supporting the follow components:

- An initial professional education in a curriculum validated by society through accreditation

- $\quad$ Registration of fitness to practice via voluntary certification or mandatory licensing

- $\quad$ Specialized skill development and continuing professional education

- Communal support via a professional society

- A commitment to norms of conduct often prescribed in a code of ethics

According to Abbot [3] professions begin when people recognise that they are undertaking a vocation/occupation that is not covered by any existing profession. Perhaps this is the current state of the ICT industry. The creation of a professional association/society defines the extent of practices and necessary competencies to perform those practices - thus defining a "competence territory" (see [2]). The process, or life cycle, of professionalisation typically consists of the following steps/phase (not in strict order):

- Create a full time occupation/vocation.

- Establish professional association.

- Create and enforce code of ethics.

- Control use of the (profession's) name and the body of knowledge (BOK).

- Develop recognised training procedures. 
- Win political, social, and legal recognition.

A profession provides comfort/security to people who fulfil its requirements and obey its tenets. However, professionalisation can often be very torturous and long drawn out simply because of other existing professions. Even when the first five steps of professionalisation stated above are largely fulfilled, gaining political, social and legal recognition can be a serious problem for the associated professionals - software engineering is a good example of such a profession. The status of a profession can change significantly with time, especially when it becomes too protective of its members and doesn't respond appropriately to serious challenges - of (say) mal-practice. Giving any impression to society of cover-ups and lack of interest in upholding codes of ethics can only damage a profession. Charges of malpractice need to be investigated without bias or conflicts of interest by professions, and the processes of investigation need to be transparent. Of course, this may be considered a simplistic stance in that there are often mitigating circumstances for what appears to be malpractice. Additionally, because of the environments in which they work, many professionals are placed under significant pressure to behave unprofessionally, typically by non- or semi-professionals.

With time, professions are also affected by changing political, social and legal environments, and if they are too slow to move with those types of external changes, they may suffer diminished recognition. The AMA Handbook on Project Management [2] presents the concept of semiprofessions by examining the state of the occupation of Project Management using the traits of a profession from Table 4. Table 5 represents a summary of that examination.

\begin{tabular}{|l|l|}
\hline $\begin{array}{l}\text { Exclusive control - esoteric and systematic } \\
\text { BOK (body of knowledge) }\end{array}$ & $\begin{array}{l}\text { NO - BOKs are beginning to be recognized but } \\
\text { still highly contested. }\end{array}$ \\
\hline Autonomy of practice & $\begin{array}{l}\text { NO - Members contribute to the standards of } \\
\text { practice. }\end{array}$ \\
\hline Norm of altruism & $\begin{array}{l}\text { NOT USUALLY - Societal impact of failed } \\
\text { projects not recognised. }\end{array}$ \\
\hline Authority over clients & $\begin{array}{l}\text { NOT USUALLY - Project Managers tend to } \\
\text { work within corporations. }\end{array}$ \\
\hline Distinctive occupational culture & POSSIBLY - Certain aspects exist. \\
\hline Recognition & $\begin{array}{l}\text { NOT YET - PM not legally recognized as a } \\
\text { profession in any jurisdiction. }\end{array}$ \\
\hline
\end{tabular}

Table 5: The Status of Project Management as a Profession - From the American Management Association's Handbook of Project Management [2].

After having (myself) attempted to elicit (without success) a specific ICT BOK it would seem that the state of the ICT profession is similar to that of Project Management - it is a semi-profession because, as summarised in Table 6, there are elements of the 'required' traits, described in Table 4, that are not completely apparent. Certainly ICT 'practice' is at the stage in the professionalisation path of being a full-time occupation/vocation. Splitting ICT into the apparent components of IT and Communications. There is at least one core/common IT body of knowledge (Australian Computer Society) but there seems to be no obvious Communications BOK - although there is a WEBOK 
(Wireless Engineering BOK within the IEEE Communications Society). As an aside, the term 'body of knowledge' seems relatively new and so many older professional societies may either use an alternative term or not actually refer to any specific knowledge base. The latter is probably due to an acceptance that (tertiary) educational institutions will provide the primary body of knowledge to support a society and its membership. So, identifying bodies of knowledge that might underpin a professional society may not always be straight forward.

A BOK is very important to a professional society, not only in defining/creating bounds to essential knowledge of members, but also in helping to define required education/training programs for basic/extra qualifications for members at different levels of the society. The BOK may in fact enable the identification of several related occupations/vocations for which different certification programs might be defined. It is one of the essential elements that a profession's membership should control, and be prepared to consider, now and then, with changing technology and societal concerns.

One of the important duties of a professional society is to ensure non-ambiguity of the name of the profession. A case in point is the profession of software engineering within Australia. Aside from the fact that computer scientists possess a different view of what software engineering is, there is also the issue that despite Engineers Australia accrediting software engineering degrees, there is no apparent support to disambiguate either the typical industry or the computer scientific usage of the name. Ambiguity of a profession's name can be damaging to the professionals who have decided to be educated/trained for the profession only to find themselves competing for positions apparently advertised for them, but open to those who are either less qualified or from different professions. Recognition of the profession externally becomes more difficult when recognition internal to a professional society is not obvious.

A professional society's code of ethics is intended to ensure its members maintain competency and appropriate behaviour and consideration toward other professionals, clients and the community. Together the BOK and the code of ethics are important in both the mounting of, and defence against charges of unprofessional behaviour. Any charge of misconduct etc. against a professional can only be successful if it is proved that best practices have not been followed and that codes of ethics have been contravened. Defence of charges follow the opposite view. If unprofessional behaviour is proved then appropriate penalties should be imparted.

All well and good, but I have only ever heard of one person in the Australian ICT industry being punished for misconduct - and then completely independent of any professional body. Are there no/few charges concerning professional misconduct in ICT? Are the associated professional bodies defending charges so successfully that very few have been actually punished for professional misconduct. Is it that legal processes are more likely to ascertain charges of professional misconduct and also deliver penalties - perhaps using associated ICT professions' BOKs and codes of ethics to do so?

Don Gotterbarn [7] relates stories of people working in the ICT/software industry who having been fired because of unethical practices, but with no intervention by appropriate professional societies to neither condone the company that instigated the act, nor impede/prevent the perpetrators of the unethical act(s) in simply moving to similar jobs at other companies.

Is it any wonder that there are sceptics concerning professionalism and professions. For example, according to Prof. John Quiggin [5]: "Professionalism is both an individual characteristic and an 
ideological position. The primary definition is that of individual professionalism: the idea that membership of a profession carries with it a set of internalised values that will be reflected in the way in which work is carried out and the ethical standards that are adhered to". A statement seeming to support the concept of professionalism.

\begin{tabular}{|l|l|}
\hline $\begin{array}{l}\text { Exclusive control - esoteric and systematic } \\
\text { BOK (body of knowledge) }\end{array}$ & $\begin{array}{l}\text { NOT FULLY APPARENT - There are } \\
\text { contributing BOKs such as SWEBOK and } \\
\text { possibly the ACS IT Core BOK, but there } \\
\text { doesn't seem to be a specific BOK for ICT. } \\
\text { University degrees confuse the situation } \\
\text { because of little consistency on base } \\
\text { knowledge/courses. }\end{array}$ \\
\hline Autonomy of practice & $\begin{array}{l}\text { NO - Members sometimes contribute to the } \\
\text { standards of practice, but not necessarily for } \\
\text { community interests. }\end{array}$ \\
\hline Norm of altruism & $\begin{array}{l}\text { NOT USUALLY - Still a general lack of best } \\
\text { fit of overall approaches and technological } \\
\text { decisions, and many ICT projects still fail on } \\
\text { cost and achievement of deadlines. }\end{array}$ \\
\hline Authority over clients & $\begin{array}{l}\text { NOT USUALY - ICT Professionals tend to } \\
\text { work to other (non)professionals who control } \\
\text { the client relationship. }\end{array}$ \\
\hline Recognition & $\begin{array}{l}\text { POSSIBLY - Certain aspects exist, but the } \\
\text { norms, values and symbols are confused. Partly } \\
\text { because ICT is a multi-profession profession. }\end{array}$ \\
\hline Distinctive occupational culture & $\begin{array}{l}\text { SEEMINGY - ICT is assumed to be a } \\
\text { profession, or at least it is often referred to in } \\
\text { that way. }\end{array}$ \\
\hline
\end{tabular}

Table 6: The Possible Status of the ICT Profession - This is the opinion of the author and is based on a combination of long-term observation and the seemingly confused state of an ICT BOK.

However, Quiggin goes on to say that the idea of professionalism as an individual characteristic is false - given the chance to pursue their own self-interest (narrowly defined to exclude such items as the approval of professional peers) individuals will do so regardless of any attempts to instill professional values. He also quotes the words of George Bernard Shaw, "The professions are a conspiracy against the laity". "That is, adherence to professional values and ethics serves to advance the collective interests of the profession at the expense of society as a whole. Exactly the same critique is made of trade unions."

When it comes to the ICT profession/professionals, I don't altogether agree with Quiggin. I rather think that the ICT profession is nebulous in terms of BOK and lacks authority or the right sort of 
recognition to ensure professional behaviour of anyone (society members and/or non-members) practising in the ICT industry. I'll come back to this point later in the paper.

Personally, I believe it is appropriate for professions to set expectations of knowledge, competence and behaviour. Professions and the professionals within them should all encourage continuous learning, sharing of knowledge, informing of experiences, and reflection on episodes of good (and perhaps bad) ethical behaviour and the benefits (or disbenefits) to others and themselves.

Establishing and maintaining a BOK and a code of ethics are the easiest activities for a profession to undertake. Because humans are the enablers and disablers of professionalism, there is always going to be a spectrum of acquired knowledge, ethical behaviours and personalities, ranging from high competence, high ethical behaviour, and very empathetic, earnest individual professionals down to just being competent enough, on the border line of ethical, and somewhat unpleasant individuals who perhaps should change their profession.

The most difficult activities for a professional society to undertake seem to be related to maintaining the integrity of its membership (using the criteria of Table 1 and the traits of Table 4 as guides). I believe, and indeed have met several people working in the ICT industry who rate as professionals according to Table 1. However, I don't currently know of any ICT type professional body, that maintains any but a few of the traits listed in Table 4.

\section{SOME CONCLUSIONS ABOUT THE STATE OF ICT}

\section{PROFESSIONS/PROFESSIONALISM}

So far I have concentrated on trying to establish what a professional is (independent of vocation) and what a profession is. I've used the definitions that I've found in order to establish that (really) the ICT profession is very young and is slowly evolving. In answering the question: "What is an ICT professional anyway?” I have to admit I'm still not sure, but I think I have a reasonable idea of the sort(s) of knowledge, competence and ethics that someone who is labelled as an ICT professional, should possess. However, I do not have a definitive answer. In perusing the ACS Core BOK for IT Professionals, I'm not sure that I am helped in answering the posed question. The ACS BOK contains the following diverse areas of knowledge:

- Computer Organisation and Architecture

- Conceptual Modelling

- Database Management

- Data Communications and Networks

- Data Structures and Algorithms

- Discrete Mathematics

- Ethics/Social Implications/Professional Practice*

- Interpersonal Communications*

- Program Design and Implementation

- Project Management and Quality Assurance*

- Security

- $\quad$ Software Engineering and Methodologies 
- $\quad$ Systems Analysis and Design

- Systems Software

The asterisks above indicate mandatory knowledge for all professional level IT courses accredited by the ACS. Any one of listed areas of knowledge could constitute a lifetime of professional activity/work, and indeed such professionals exist. For example, within the Software Engineering and Methodologies area of knowledge there is another recognised BOK (SWEBOK - Software Engineering BOK [4]) and it contains the following knowledge areas:

- Software requirements

- Software design

- Software construction

- Software testing

- $\quad$ Software maintenance

- Software configuration management

- Software engineering management

- $\quad$ Software engineering process

- Software engineering tools and methods

- $\quad$ Software quality

Again, any one of these knowledge areas could occupy a lifetime of professional activity/work, and again, such professionals exist. As indicated earlier, it is appropriate to define a BOK. However, it is also appropriate to define levels of practice. The SWEBOK [4] does include descriptions of practices and processes for each of its knowledge areas, but does not define levels of practice. At this stage the ACS Core BOK for IT Professionals contains little in the way of appropriate practices/processes for each of the areas of knowledge nor anything about levels of practice. This is not intended to be a criticism, the SWEBOK took 6-7 years to define, and with the help of well over 500 professionals. However, it does show that the ACS BOK is not yet complete.

It seems appropriate that anyone possessing significant capability surrounding any one of the knowledge areas of the SWEBOK might be an eligible ICT professional. However, they'd obviously have to possess significant understanding of other (related) knowledge areas in order to do their jobs comprehensively. So what minimum depth of overall knowledge would anyone need to reach some base level of practice enabling professional status in (say) software testing? Also, what other higher levels of practice might these base level professionals aspire to, that is both defined and supported by an ICT professional society?

I could conclude by simply stating that I do not believe the ICT profession, as it stands today, is or is even capable of providing adequate support to ICT professionals and non-professionals. Until that happens I doubt I or anyone else will be able to answer the question - "What is an ICT Professional, anyway?" However, whilst this conclusion may be correct, it neither helps in maturing the ICT profession further, nor in providing less confusion for those working as professionals and non-professionals in the ICT industry. 


\section{FURTHER WORK}

It is apparent that significant work needs to be done to fully establish an appropriate ICT BOK and associated practices. To that extent, it should be noted that the Australian Computer Society (ACS) is currently in the process of establishing a more comprehensive BOK than is currently available. This endeavour is important for the ACS because (as a professional body) it accredits tertiary IT programs throughout the country. In this prosess, existing BOKs such as SWEBOK, which provides a very good basis for describing base knowledge, methods and practices for each of its knowledge areas, need to be taken into account,.

In this and other related BOK endeavours, a need exists to ensure input to the process by a broad range of stakeholders - not (say) just academics. The mixture of stakeholders needs to include people and organizations who are not only creators of ICT-related knowledge, products or services, but who are the users/receivers and/or who are impacted in some way.

Regarding the matter of codes of ethics, it seems that most professional societies provide these, mostly as guidelines of acceptable behaviour and also as a basis for examination of accusations of unprofessional behaviour. On the one hand, codes of ethics can be used as blunt instruments, only to be made apparent when a professional member has committed some (alleged) malpractice. On the other hand, codes of ethics should be used to actively encourage greater, unwavering commitment to dedication, integrity, honesty and trustworthiness. Obviously to establish a profession containing highly professional members requires education, not just to learn the wording of codes of ethics but also learn to use the codes of ethics as a framework to clearly promote what is expected of professionals and how they should behave in any given circumstance when ethical behaviour is at risk. All this is easily stated but hard to do. Nonetheless ethical behaviour needs to be imparted and governed effectively in order to raise the bar on expectations of all ICT stakeholders in regard to ICT activities.

So, it seems that ICT professional bodies currently need an injection of governance practices, especially in being proactive about supporting current members and expanding membership to help ensure wider consistency of professional behaviours, appropriate practices and projects' outcomes. In Australia there is evidence that this is happening.

Aside from dealing with the $\mathrm{BOK}$, ethical behaviour and expectations, there is the matter of determining different levels of practice/skills regarding the broad range of capabilities among people working in the ICT industry. Some of the ICT types I described at the beginning of this paper may better fit the job description of "technician" rather than (say) "engineer" or "scientist". All of these roles should, of course, follow professional practices and abide by ethical standards. However, the purpose in providing a range of levels of practice is to set in place a reasonable framework to establish minimum requirements for being able to practice as a particular type of ICT professional, and also determine what 'endorsing' criteria need to be met to advance to higher levels of practice.

The concept of levels of practice is certainly not new, and has the same 'old' advantages within other more established professions of protecting all stakeholders. For example, it should not be possible for a new graduate of the ICT profession to be placed in a managerial role requiring significant technical and people management experience, to be handling significant numbers of staff (including senior staff), and to also be expected to make technical decisions on topics of which they 
only possess no/superficial knowledge. I have seen this occur on several occasions, and the result is usually not pretty because it affects a significant body of stakeholders, including the junior professional and the organization employing them. The junior can be "scarred' for life professionally, and the organization for which they work rarely takes the blame for the inevitable failure(s). This sort of situation is caused through the combination of lack of ethics (of both parties) and an undetermined limitation to a role in which a junior ICT professional can be involved. Ethically, junior professionals must be able to both admit their inability and to resist the temptation/encouragement to be involved in a role for which they do not have the requisite knowledge or skill. Ethically, the organization should not be able to advise a junior professional to undertake a role for which they do not possess the appropriate capability.

So, if the ICT profession is to gain traction as a true profession supporting true professionals, then steps need to be made now along the lines described above. The magnitude of such a task may seem insurmountable just now, and indeed it will take some significant time to evolve. The point is that the first steps need to be undertaken as soon as possible so as the ICT profession maintains/improves the recognition as a profession which it currently does not deserve.

\section{REFERENCES}

1. Texas Library Service Training Program http://www.tsl.state.tx.us/ld/tutorials/professionalism/prof.html

2. Paul Dinsmore and Jeanette Cabanis-Brewin; The AMA Handbook of Project Management ( $2^{\text {nd }}$ Edition), Chapter 18, 2006.

3. Andrew Abbot, The System of Professions; University of Chicago Press, 1988.

4. The Software Engineering Body of Knowledge http://www.swebok.org

5. Professor John Quiggin (Australian Research Council Federation Fellow in Economics and Political Science at University of Queensland) - johnquiggin.com, September 2003.

6. John Ridge; Australian Computer Society, Opening Presentation to EtGovICT 2008.

7. Don Gotterbarn; Software Engineering Ethics Research Institute, Presentation to EtGovICT 2008.

8. David H. Maister; True Professionalism; Touchstone, 1997. 